\title{
The MYC transcription factor network: balancing metabolism, proliferation and oncogenesis
}

\author{
Patrick A. Carroll, Brian W. Freie, Haritha Mathsyaraja, Robert N. Eisenman (ه) \\ Division of Basic Sciences, Fred Hutchinson Cancer Research Center, 1100 Fairview Ave. N., Seattle, WA 90109, USA \\ (C) The Author(s) 2018. This article is published with open access at link.springer.com and journal.hep.com.cn
}

\begin{abstract}
Transcription factor networks have evolved in order to control, coordinate, and separate, the functions of distinct network modules spatially and temporally. In this review we focus on the MYC network (also known as the MAX-MLX Network), a highly conserved super-family of related basic-helix-loop-helix-zipper (bHLHZ) proteins that functions to integrate extracellular and intracellular signals and modulate global gene expression. Importantly the MYC network has been shown to be deeply involved in a broad spectrum of human and other animal cancers. Here we summarize molecular and biological properties of the network modules with emphasis on functional interactions among network members. We suggest that these network interactions serve to modulate growth and metabolism at the transcriptional level in order to balance nutrient demand with supply, to maintain growth homeostasis, and to influence cell fate. Moreover, oncogenic activation of MYC and/or loss of a MYC antagonist, results in an imbalance in the activity of the network as a whole, leading to tumor initiation, progression and maintenance.
\end{abstract}

Keywords network; transcription; cancer; MYC; MAX; MLX

\section{Introduction: biological networks}

Networks, in diverse fields including computer sciences, telecommunications, sociology, and biology, are generally defined as clusters of distinct nodes connected by what are termed "edges." In biology, complex systems are frequently represented in terms of networks which can be subdivided into smaller groups or modules thereby revealing key relationships that underlie network activity $[3,4]$. The ubiquity of network organization reflects its potential to deploy interactions and functions in spatially and temporally determined patterns and to accommodate both antagonism and synergy among network components. Moreover, networks often possess "tipping points" whereby the loss- or gain-of-function of an individual network member may act to alter or distort the activity of the network as a whole. These concepts have been applied to intermediary metabolism, neural circuits, signal transduction pathways, developmental programs, immune systems, and transcriptional regulatory mechanisms. In

Received March 2, 2018; accepted May 21, 2018

Correspondence: Robert N. Eisenman, eisenman@fhcrc.org the area of transcriptional regulation, well studied examples of networks include the genes and their encoded proteins that drive the circadian clock [6], induce pluripotency $[7,8]$, and determine commitment to $\mathrm{T}$ lymphocyte differentiation [9]. In this review we focus on the MYC transcription factor network (also known as the MAX-MLX Network or the Extended MYC Network) which has been strongly implicated in normal cell growth and proliferation and in the etiology of a wide range of cancers.

\section{Components of the MYC network}

Fig. 1 depicts one way to organize the components of the MYC network, all of which have the capacity to function in gene transcription and possess a highly conserved protein-protein interaction and DNA binding domain known as a basic-helix-loop-helix-zipper (bHLHZ). In its simplest sense this network can be thought of as possessing three major nodes with distinct inputs and transcriptional properties: (1) MYC family proteins; (2) proteins in the MXD family (as well as MNT and MGA); and (3) the MLXIP and MLXIPL proteins (also known as MondoA and ChREBP, respectively). Each of these network 


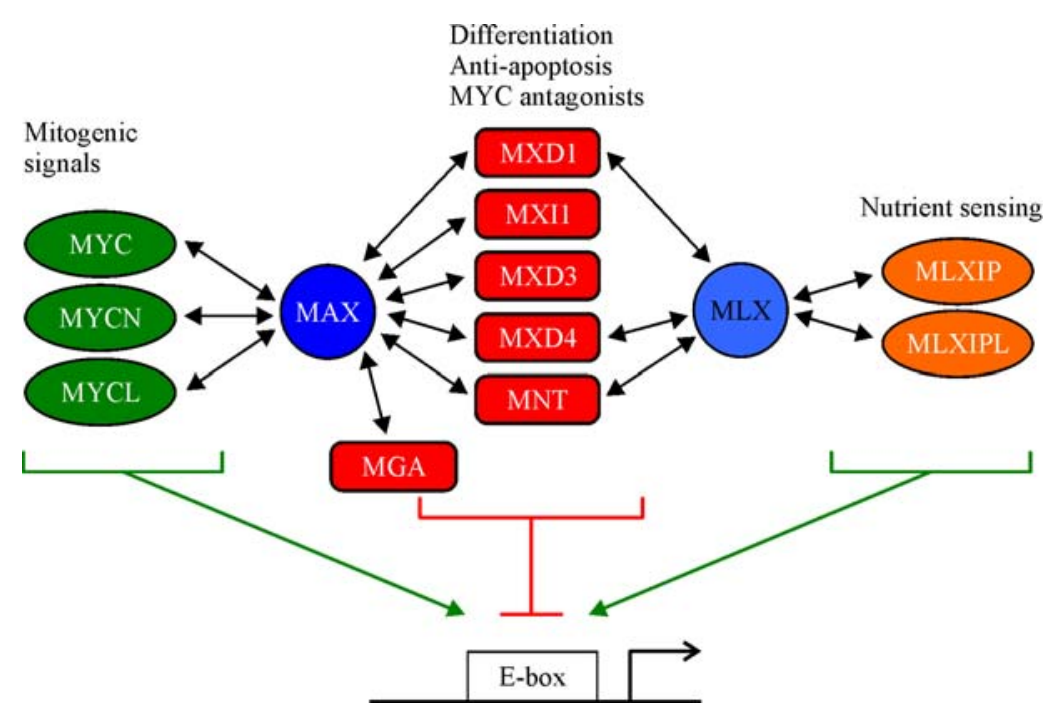

Fig. 1 The MYC network showing the three modules from left to right-MYC; MXD/MNT/MGA; and MLXIP/MLXIPL and the dimerization interactions with MAX and/or MLX (indicated by double-headed arrows). The resulting heterodimers bind to E-box sequences in DNA.

proteins employs its bHLHZ domain to form an individual heterodimer with the bHLHZ domains of either MAX, MLX or both (see Fig. 2 for crystal structures of MYCMAX and MXD1-MAX bHLHZ domain heterodimers). It is heterodimerization with MAX and/or MLX that constitutes the functional edges of the network. In what follows we summarize the nature of the MYC network modules and focus on the functional interactions among modules (for recent reviews on the MYC network see $[5,10-13])$.

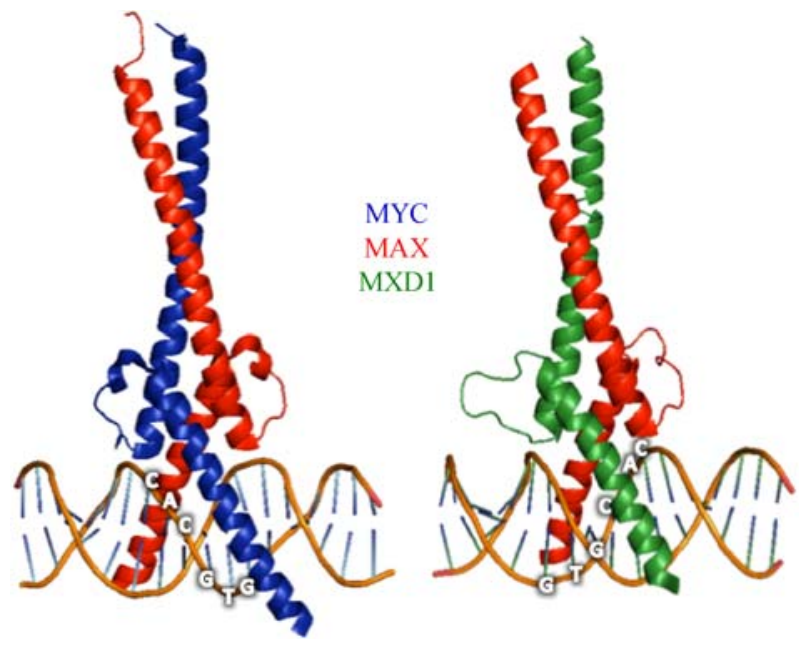

Fig. 2 Crystal structures of the bHLHZ domains of (left) MYC-MAX heterodimer (PDB:INKP) and (right) MXD1-MAX heterodimer (PDB: INLW) bound to E-box DNA (5'-CACGTG-3') at $19 \mathrm{~nm}$ and $2 \mathrm{~nm}$ resolution, respectively [1]. Image created with the PyMOL Molecular Graphics System, Version 1.5.0.4, Schrödinger, LLC.

\section{MAX and MLX}

Both MAX and MLX were discovered through independent protein interaction screens that sought to identify dimerization partners for MYC [14] and for MXD1 [15] respectively. The amino acid sequences of the bHLHZ domains of MAX and MLX are related to each other ( $\sim 50 \%$ identity), and also show significant similarity to the bHLHZ domains of all of the MYC network proteins. Outside of their bHLHZ domains MAX and MLX do not exhibit significant homology with each other or with other network members. Importantly, the heterodimerization specificity of MAX and MLX for different network members is restricted, as indicated by the double-headed arrows in Fig. 1. MAX dimerizes with all three MYC family proteins (MYC, MYCN, MYCL) and all six of the MXD/MNT/MGA family proteins, while MLX dimerizes with only a subset of the MXD family (MXD1, MXD4, and MNT) as well as with MLXIP and MLXIPL $[12,13]$. Fig.2 shows the structures of the bHLHZ heterodimer interfaces bound to E-box DNA of MYC-MAX and MXD1-MAX [1]. For proteins such as MNT, that are capable of dimerizing with either MAX or MLX, it appears that the two types of heterodimer are equivalent in terms of DNA recognition and transcriptional activity. However more detailed biophysical analysis of the binding constants related to dimerization and DNA recognition of the different complexes remain to be carried out.

Unlike MYC, MAX is capable of forming homodimers but these are inhibited from binding DNA in vivo due to phosphorylation by casein kinase II [16]. Furthermore structural differences in their leucine zipper regions dictate that MAX preferentially heterodimerizes with MYC or MXD rather than form MAX-MAX homodimers [1]. MLX 
and its several isoforms have also been reported to homodimerize and bind E-Box DNA but possess negligible transcriptional activity, as is the case for MAX homodimers [17]. Therefore, it is likely that the primary functions of MAX and MLX are to drive formation of heterodimers and facilitate their ability to specifically recognize DNA.

Both MAX and MLX are stable proteins in vivo with half-lives on the order of 6-8 h, while MYC, MXD, MNT, and MGA have considerably shorter half-lives, generally less than $1 \mathrm{~h}$ (dependent on cell type) suggesting that they are rate-limiting for heterodimer formation [18-20](H.M. unpublished data). Not surprisingly, the accumulation of these short-lived proteins is highly regulated and dependent on several factors. These include their rates of gene expression, RNA half-lives, and translation efficiencies - all processes closely linked to environmental and intra-cellular signaling. Interestingly the MLXIP and MLXIPL proteins are relatively stable compared to the MYC and MXD family proteins - possibly reflecting the fact that their regulation derives in part from their ability to shuttle between nucleus and cytoplasm (see below). The differing half-lives, localizations, and the dependence on signaling pathways are important contributors to the dynamic nature of the MYC network and its role in gene expression [10,21].

MAX serves as a network edge between MYC and the MXD/MNT/MGA family. MLX acts similarly for MXD1, MXD4 and MNT and the MLXIP/MLXIPL proteins, which comprise the third branch of the MYC Network $[15,22]$ (see Fig. 1). Because MAX, MLX and all of the proteins in the MYC network each contain only a single bHLHZ domain, MAX and MLX do not physically connect the modules to each other. Rather, within the cellular populations of MAX and MLX proteins, individual dimerization interactions with different module members occur, based on their abundance, affinity, and localization. The heterodimers thus formed must access DNA to exert their transcriptional activities which in turn determines the overall activity of the network. In the following sections we briefly describe the properties and activities of the MYC network modules.

\section{The MYC module}

The MYC protein family (comprised of MYC, MYCN, and MYCL) can be considered the founding members of the MYC network. The MYC gene was initially discovered as a oncogene (denoted $\mathrm{v}-m y c$ ) present in the genomes of a small group of avian retroviruses responsible for transformation of fibroblast cells in tissue culture and for different types of hematopoietic neoplasms in animals. It was subsequently determined that the v-myc gene was derived by retroviral acquisition of the cellular MYC gene [23,24]. Further studies showed that the cellular MYC gene (and its paralogs $M Y C N$ and $M Y C L$ ), while having critical functions in normal animal growth and development, are subject to frequent alterations in a significant fraction ( $>30 \%$ ) of human cancers comprising a wide range of tumor subtypes [25]. The alterations in $M Y C$ family genes include gene amplifications, chromosomal translocations, viral integration, and regulatory mutations in $M Y C$ promoter or enhancer regions. Much evidence has accumulated indicating that the alterations in $M Y C$ are associated with key stages of tumorigenesis including initiation, progression, and maintenance. Despite the plethora of genetic rearrangements occurring at the $M Y C$ locus, the vast majority of these do not directly affect the MYC protein coding region. This is consistent with the notion that it is the deregulation of MYC expression, rather than altered or neomorphic changes in its protein function, that is at the root of MYC driven cancers [26,27].

\section{MYC deregulation}

The significance of deregulation of MYC expression in cancers became clearer when it was understood that in normal cells MYC family genes are both directly and indirectly controlled by multiple signal transduction pathways that are in turn activated by external and internal stimuli such as growth factors, mitogens, or cytokines. Many of these pathways induce MYC gene transcription as an immediate early response (i.e., not requiring protein synthesis) to mitogenic signals. For example, treatment of quiescent fibroblast cells with mitogens results in the rapid induction of MYC mRNA and protein associated with cell cycle entry $[28,29]$. Many mitogenic signal transduction pathways directly lead to the activation of transcription factors that engage $M Y C$ enhancers and promoters. Other factors regulate MYC mRNA transport, half-life and translation. Moreover, MYC protein levels are maintained by a balance between synthesis and regulated degradation. Importantly, in many cancers in which $M Y C$ family genes are rearranged, the tightly regulated control of MYC expression is frequently lost, resulting in constitutive expression of MYC at high levels compared to most normal cells (with the exception of normal cells during periods of high proliferative and metabolic demand, e.g., $\mathrm{T}$ cell activation [30]). Thus in many cancer cells MYC becomes insulated from environmental signals, the abundance of its gene products increases and it fails to be downregulated in response to appropriate signals for growth arrest and differentiation (for reviews see [10,31]). Indeed with some exceptions (e.g., where MYC loss induces a dormant state [32]) enforced downregulation of MYC in many tumors leads to regression [33,34].

\section{Transcriptional regulation by MYC-MAX}

As mentioned above, MYC family proteins function as 
transcriptional regulators. Heterodimerization with MAX through the HLHZ regions of both proteins permits the dimeric basic regions to form induced-fit helices that recognize the symmetric DNA sequence CACGTG (Fig. 2 and Fig. 3). This sequence, which is likely to be preferentially bound by all members of the network, belongs to the more general class of E-box sequences (CANNTG), variants of which are also recognized by MYC-MAX at lower affinity relative to the canonical CACGTG. DNA sequences harboring potential E-box binding sites are relatively frequent in the genome. For example, the canonical CACGTG sequence is present approximately every 4 kilobases. In cells, binding to genomic E-box-containing DNA is dependent on chromatin structure. The presence of histone $\mathrm{H} 3$ trimethylated at lysine position 4 relative to the $\mathrm{H} 3 \mathrm{~N}$ terminus (H3$\mathrm{K} 4 \mathrm{me} 3$ ) and of other DNA binding proteins such as WDR5 have been shown to facilitate MYC-MAX binding [35,36].

While MYC-MAX heterodimers directly bind to DNA, they also recruit other proteins to genomic E-boxes. In general, these are factors that mediate transcription (Fig. 3). Several of these are associated with the Nterminal transcription activation domain of MYC, such as the NuA4 complex which contains the histone acetyl- transferase GCN5, the pTEFb RNA polymerase pauserelease complex, and other factors that remodel chromatin and promote transcription. Other factors, such as $\mathrm{POZ}$ domain transcription factor MIZ-1, bind the MYC-MAX heterodimeric interface region [37] and can significantly influence the transcriptional and biological activity of MYC-MAX [38]. The specific factors bound and their functions at genomic binding sites are likely to depend on the exact biological context [39]. Recent studies indicate that MYC-MAX binds and amplifies cell-type specific gene expression programs [40-42]. In addition, deregulated, overexpressed MYC in several tumor types binds to low-affinity non-canonical E-boxes and associates with high-density enhancers (super-enhancers) to promote expression of distinct gene subsets [40,43-47]. In other words, deregulated MYC can bind MAX and alter normal ongoing gene expression programs to impose a tumorspecific transcription profile.

In taking an overview of the MYC family branch of the network it is reasonable, as a first approximation, to view it as a protein module that integrates mitogenic signals from diverse sources and enables initiation and/or reinforcement of gene expression programs compatible with the cellular environment and the maintenance of cell fate during growth and division.

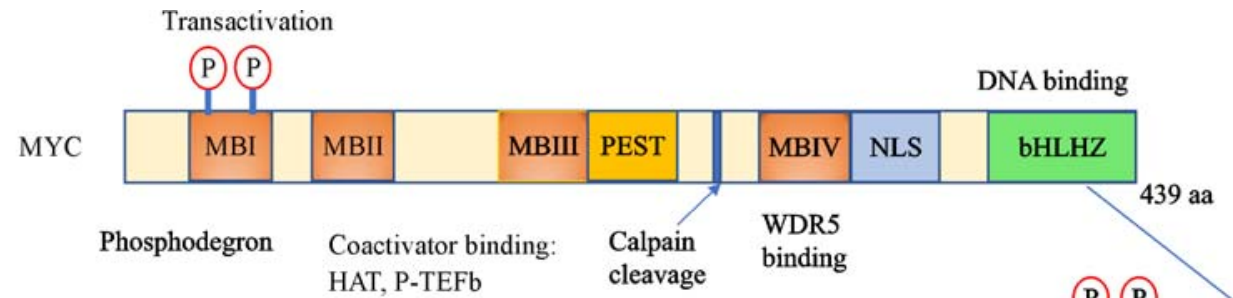

HAT, P-TEFb cleavage binding

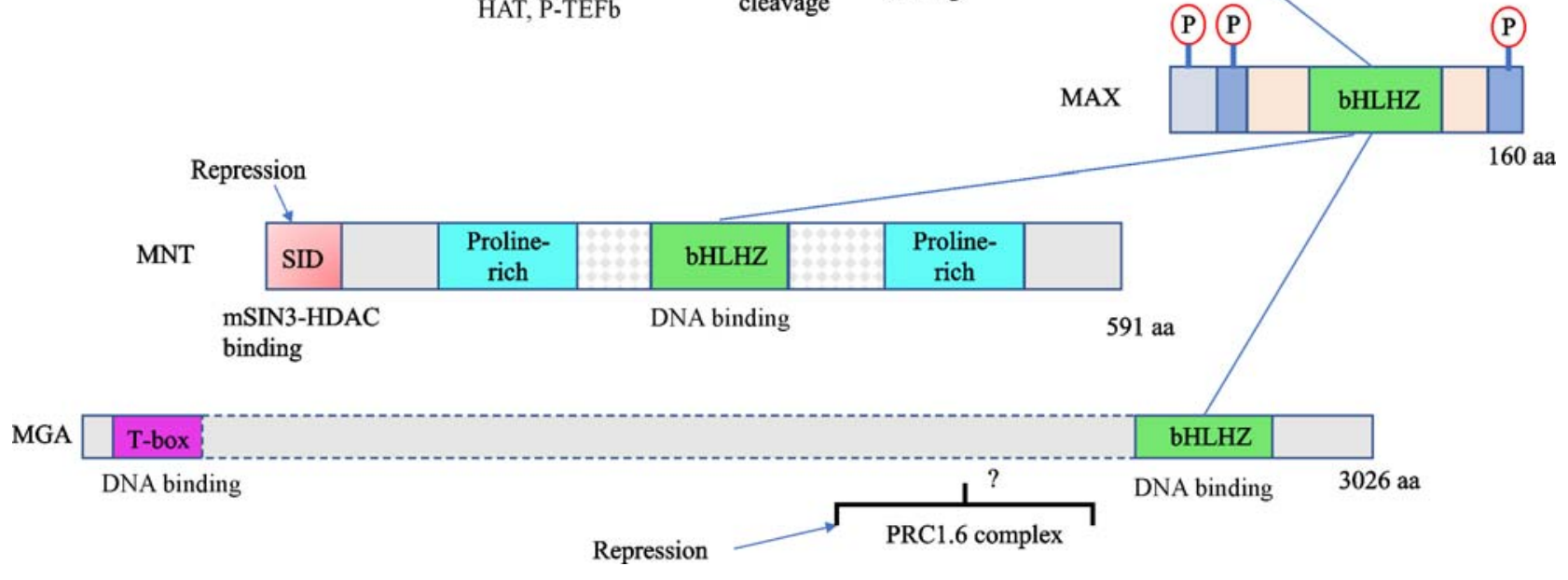

Fig. 3 Organization of the MYC, MAX, MNT and MGA proteins. Heterodimers are formed by direct interaction of the basic-helix-loop-helixzipper (bHLHZ) domain of MAX with the bHLH-Z domains of either MYC, MNT or MGA (blue lines). Number of residues in each protein indicated at C terminus. MYC: MBI-IV — conserved MYC boxes; PEST - region rich in proline, glutamic acid, serine and threonine; NLS - nuclear localization sequence; Calpain cleavage site — proteolytic cleavage to generate MYC-Nick [2]. MNT: SID — binding site for the mSIN3 co-repressor complex. MGA: repression mediated through assembly into a variant polycomb repressor complex (PRC1.6). Question mark indicates that the region of MGA that directly interacts with the complex is unknown. Protein lengths not to scale. See text for details. 


\section{The MXD/MNT/MGA module}

In addition to forming heterodimers with MYC family proteins, MAX heterodimerizes with all members of the MXD family (MXD1, MXI1 (MXD2), MXD3, and MXD4) and the related MNT protein, each of which possesses a bHLHZ region [18,48-51] (Fig. 3). Moreover Max dimerizes with the bHLHZ domain of the MGA protein, the largest member of the MYC network, which also contains a functional T-box DNA binding region [52] related to the Brachyury/Tbx proteins, a family known to play key roles in early vertebrate development [53-55] (Fig. $3)$. The MAX heterodimers formed with each of these proteins bind canonical E-box DNA similar to MYC-MAX dimers and crystallographic studies indicate that the bHLHZ dimeric interfaces are nearly identical (limited to MAXMAX; MYC-MAX, and MXD1-MAX) [1,56] (Fig. 2).

It is not entirely straightforward to ascribe a broad functionality to the MXD/MNT/MGA module as a whole. While their heterodimerization with MAX and their ability to bind E-box DNA might suggest that the MXD/MNT/ MGA module functions similarly to the MYC module, a great deal of evidence argues against this idea. Indeed, MXD/MNT/MGA appear to act as antagonists of MYC function. First, whereas MYC-MAX binding predominantly promotes or reinforces active transcription (see above), the MXD/MNT/MGA module proteins act as transcriptional repressors. The MXD family members and MNT contain a short conserved amino acid sequence, which directly interacts with mSIN3A or mSIN3B corepressor complexes [18,49,57,58]. mSIN3 acts as a platform upon which multiple proteins that mediate gene silencing are assembled. Most notably, these include Class I histone deacetylases (HDAC1 and HDAC2) that enzymatically remove acetyl groups from histones $\mathrm{H} 3$ and $\mathrm{H} 4$, thereby contributing to silencing of active chromatin [59-61] (Fig. 3). By recruiting mSIN3-HDAC co-repressor complexes to their genomic binding sites, $\mathrm{MXD} / \mathrm{MNT}$ proteins appear to antagonize or reverse the transcriptional activity of MYC family proteins which, as noted above, recruit co-activator complexes leading to the acetylation of histones $\mathrm{H} 3$ and $\mathrm{H} 4$, characteristic of active chromatin (see below for discussion of antagonism).

\section{MGA}

MGA (pronounced mega) stands somewhat apart from the MXD/MNT family due to its large size (with $>3000$ residues MGA is $\sim 14$ fold larger than the MXD family and 5 fold larger than MNT) and the presence of both bHLHZ and T-box domains (Fig. 3), as well as its apparent ability to both activate or repress transcription in a context dependent manner [52]. While, like the other MXD/MNT family factors, MGA attenuates MYC-induced cell transformation it does not contain a mSIN3 binding domain. Interestingly however MGA-MAX has been shown to comprise a subunit of a variant Polycomb complex (PRC1.6) which suppresses meiosis in germ cell development and is almost certain to possess other functions [62-66]. Moreover MGA, unlike MXD family proteins, is essential for early embryonic development and has been shown to be involved in embryonic patterning and maintenance of pluripotency [67-69]. In addition, MGA sustains genomic alterations, including indels and point mutations in a range of human tumors at a high frequency relative to MXD/MNT. A subset of these alterations is predicted to inactivate the MGA bHLHZ domain proximal to its $\mathrm{C}$ terminus [70-74]. The prevalence of potentially inactivating mutations as well as its ability to oppose MYC transforming activity, makes MGA a strong candidate for functioning as a tumor suppressor.

\section{MLX and the MLXIP/ MLXIPL module}

MLX was first identified through its ability to dimerize with MXD1, MXD4 and MNT (but not to MXD2/MXI1, MXD3 or MGA) [17,22]. Moreover, MLX does not dimerize with either MAX or MYC family members. Importantly, later work revealed that MLX forms heterodimers with two large bHLHZ proteins: MLXIP (MondoA) and MLXIPL (ChREBP or MondoB) (referred to here collectively as MLXIP proteins) [22] (Fig. 4). The structural basis for the unique binding specificity of MLX is unknown but it has been suggested that a conserved tyrosine residue in the leucine zipper of the MLX bHLHZ domain may, upon phosphorylation, permit a shift in dimerization partners $[11,66]$.

A key function of MLXIP- and MLXIPL-MLX heterodimers is to mediate the cellular transcriptional response to changes in glucose and glutamine levels. MLXIP-MLX dimers are localized to the outer mitochondrial membrane and MLXIPL-MLX dimers are present in the cytoplasm where they directly or indirectly sense G-6-P (glucose-6-phosphate) and other metabolites derived from glucose [12,75-78], relocalize to the nucleus, and bind sequences known as carbohydrate response elements (ChoREs) which are comprised of two closely spaced Eboxes [78-80]. Many of the ChoRE-containing genes bound and regulated by these MLXIP/MLXIPL-MLX heterodimers play critical roles in cellular glucose and lipid metabolism. For example, MLXIP-MLX bind to a ChoRE sequence in the promoter of the gene encoding thioredoxin-interacting protein (TXNIP) which functions in part to suppress glucose uptake and inhibit mTOR and thioredoxin (for review see [11]). In this way the MLXIPMLX-TXNIP pathway acts as a negative feedback regulator responsive to glucose stimulation and serves as a nutrient sensor, communicating information from the mitochondrion to the nucleus in order to maintain 


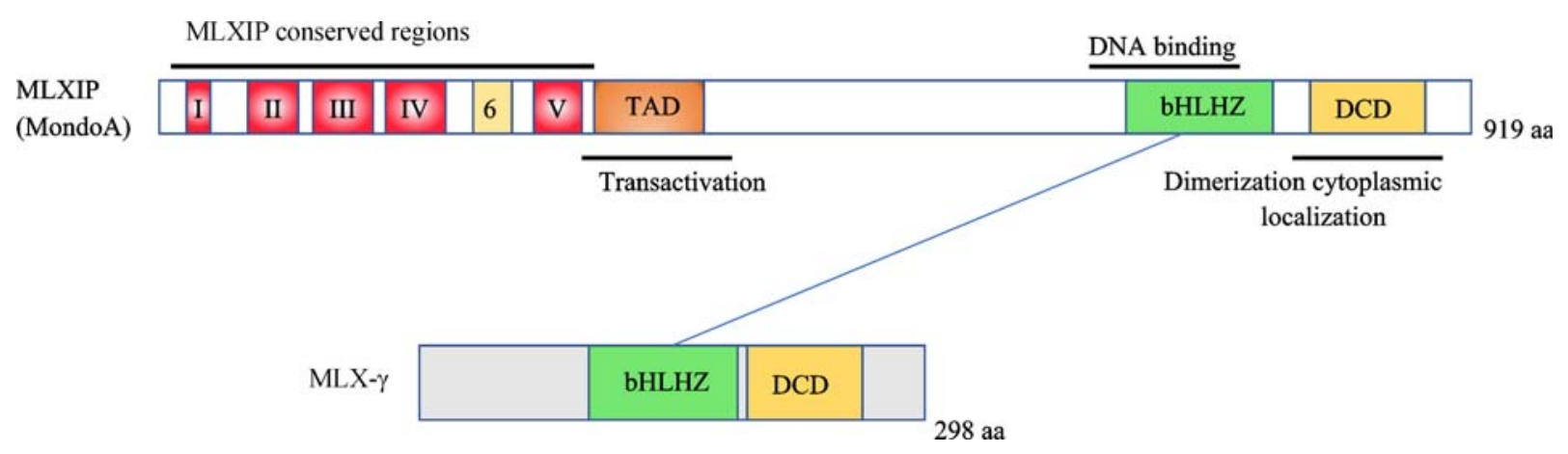

Fig. 4 Organization of MLXIP (MondoA) and MLX. MLXIP: highly conserved regions proximal to the N terminus are thought to be responsible for binding to glucose metabolites. MLX interacts with MLXIP through their bHLHZ and DCD domains. MLX has 3 isoforms generated by alternative splicing: MLX- $\gamma$ (nuclear localized), MLX- $\alpha$ and MLX- $\beta$ (both cytoplasmic).

metabolic homeostasis. The importance of this module has been underscored by studies in Drosophila melanogaster where MondoA-Mlx (orthologs of vertebrate MLXIPMLX) acts as a master regulator of the physiologic response to sugar by both directly and indirectly modulating expression of effector genes mediating lipid, carbohydrate, and amino acid metabolism [81,82]. Several Drosophila MondoA-MLX target genes have human orthologs that contain polymorphisms associated with high levels of circulating triglycerides and coronary artery disease [81]. In addition MLXIPL-MLX regulates gene expression linked to glucose and lipid metabolism, and genetic studies further implicate this heterodimer in metabolic disease and cancer (for review see [83]).

\section{MYC network dynamics and crosstalk}

We earlier mentioned that among the advantages of having an integrated network organization is the capacity to separate, control, and coordinate the specific activities of the network modules in time and space. This concept is likely to apply to the MYC network. Moreover, the notion of a "tipping point" - in which an imbalance in the regulation, abundance or activity of an individual network member may dysregulate the integrated function of the network as a whole - can be considered to apply to the oncogenic alterations leading to deregulation and increased expression associated with the MYC module (for review see [84]) as well as loss of function mutations in MAX $[71,85]$ and MNT $[86,87]$. To understand how this might occur we will briefly describe the evidence for functional interactions among network components and argue that a functional balance among network members is critical for cellular homeostasis.

\section{Functional interactions between MYC and MXD/MNT}

The notion that MYC-MAX and the MXD-MAX/MLX arms of the network may act antagonistically was initially prompted by the findings that MXD/MNT proteins contain transcriptional repression domains that recruit histone deacetylases to their DNA binding sites in chromatin while, in contrast, MYC proteins recruit complexes that promote transcription by facilitating chromatin accessibility and release of paused RNA polymerase (Fig. 3). The recruitment of distinct complexes with presumably opposing activities is the molecular basis for MYC vs. MXD/ MNT/MGA antagonism (Fig. 3) which is also manifested at the level of their biological activities. MYC family genes, when overexpressed, stimulate cellular growth and proliferation balanced by apoptosis, eventually leading to transformation and tumor formation. By contrast, there is considerable evidence that MXD1, MXD2 (MXI1), MXD4 and MNT act to retard cellular growth and proliferation and have the capacity to block MYC induced mitogenic effectors and transformation [18,49,88-91].

One setting where this antagonism serves to regulate normal cellular events is during cell cycle entry. In the G0 to G1 transition MNT-MAX levels are constant while MYC is strongly induced, resulting in an increased ratio of MYC-MAX:MNT-MAX complexes, consistent with the idea that MYC and MNT are in competition for available MAX. Either MNT overexpression or MYC loss inhibits cell cycle entry, suggesting that antagonism between these proteins and their balanced expression may set the threshold for the transition between quiescence and proliferation [92]. However, given the multiple cellular processes that are responsive to MYC, it would seem unlikely that MXD/MNT would antagonize every aspect of MYC function. For example, there is evidence for dependence or cooperation between MYC and MNT, especially in situations in which MYC levels are elevated and MNT acts to suppress MYC-induced apoptosis $[93,94]$. Another example is MXD3, which has been reported to stimulate neural cell proliferation and promote apoptosis in response to radiation damage $[95,96]$. 
Although the precise relationship of MXD3 to MYC activity is unclear, it is possible that MXD3 can cooperate with or substitute for MYC.

The above examples of functional interactions within the network occur in contexts where MXD/MNT/MGA and MYC proteins are present at the same time and in the same sub-cellular compartment. However significant interactions between MYC and MXD/MNT may also occur if the proteins in question are not simultaneously present. This is relevant considering that endogenous expression of many of these proteins are correlated with different cell cycle and differentiation states. MYC expression is predominantly, but not solely, confined to proliferating cells while MXD1, MXI1, and MXD4 are detected in resting or differentiated cells and are downregulated when cells enter the cell cycle. This inverse correlation with MYC expression does not hold for MNT, which is co-expressed with MYC but is maintained upon differentiation, when MYC is downregulated (for review see [97]). However, antagonism may occur even if the MYC and MXD/MNT proteins are not simultaneously present. For example, during terminal differentiation MYC is generally downregulated while MXD1 is sharply induced as cells arrest growth. During this period a shift from MYC-MAX to MXD1-MAX complexes is observed, leading to binding and repression by MXD1-MAX at promoters previously transcriptionally activated by MYC-MAX $[19,89,98]$. Why would repression by MXD1-MAX at these promoters be necessary if MYC is already downregulated? One likely explanation is that loss of MYC alone is insufficient to fully suppress target gene expression. Most transcription is regulated by multiple factors and at multiple levels such as chromatin mediated promoter accessibility, pre-initiation complex assembly, RNA polymerase initiation, pausing, elongation, and termination. Recent evidence suggests that MYC, rather than acting as an transcriptional on/off switch, is primarily involved in release of paused RNA polymerase II and the amplification of gene expression [41,42]. Furthermore MYC binding leads to histone acetylation and other chromatin modifications compatible with active transcription. Therefore simply removing MYC may leave certain promoters susceptible to stimulation or induction and permit them to remain active, hence the need for expression of MXD1 to reverse MYC's activity as an early event in differentiation. This concept is supported by genetic studies in Drosophila melanogaster where deletion of $d m 1$ (which encodes dMyc, the Drosophila ortholog of MYC) produces growth arrest at an early stage of larval development and diminished expression of growth related genes. By contrast, flies lacking both dMyc and dMnt (the single paralog of MXD/MNT in Drosophila) display significantly augmented growth and development accompanied by a partial restoration of the expression of dMyc activated growth genes [99]. Interestingly a similar type of rescue dynamic has been reported for other antagonistic pairs of transcription factors $[100,101]$.

\section{Regulation through degradation}

Taken together, the evidence suggests that a regulated balance between MYC and MXD/MNT factors is important in maintaining growth homeostasis in response to environmental signals (Fig. 5). In the case of the MYC module, the signals leading to induction and maintenance of MYC expression can be generally classed as mitogenic and include a broad range of growth factors and cytokines including CSF-1, LIF, Wnt, Notch, Sonic Hedgehog, EGF, and IL2. While the MXD module is generally considered to be induced by growth arrest, as well as by developmental, and differentiation signals, the specific pathways leading to MXD induction are not well defined. Because the MYC family and MXD/MNT/MGA proteins all possess relatively short protein half-lives, regulation of their degradation is also an important aspect of setting the balance between these modules. MYC degradation is mediated by several ubiquitin ligases, one of which (FBXW7), requires a specific set of phosphorylations within a phosphodegron near the MYC N terminus (Fig. 3) [102]. As these phosphorylation events are stimulated by growth factor responsive signal transduction pathways such as RAS-MAPK and PI3K-AKT-GSK3 $\beta$, it is evident that MYC degradation is responsive to environmental cues (for review see [103]). Interestingly, MXD1 has also been shown to be degraded subsequent to PI3K/AKT and MAPK mediated phosphorylation [104] suggesting that environmental signaling through these pathways may contribute to the balance between MYC and MXD arms of the network (see Fig. 5).

\section{MAX inactivation}

A loss of network balance may also come into play in the case of the surprising findings that inactivating mutations or deletions of MAX are associated with tumorigenesis, particularly involving cells of neuroendocrine origin $[71,85]$. MAX inactivation would be expected to cancel MYC's tumorigenic functions. However loss of MAX should also result in reduction or loss of MXD family, MNT and MGA binding. Although MXD1, MXD4, and MNT might still retain some activity by dimerization with MLX (see Fig. 1), the balance among network members upon MAX loss is likely to be seriously compromised, perhaps leading to aberrant activation of genes due to abrogation of MXD/MNT/MGA repression, similar to the effects observed upon double deletion of $\mathrm{dMyc}$ and $\mathrm{dMnt}$ in Drosophila as described above [99]. Another, not necessarily mutually exclusive, possibility is that MYC can retain certain critical functions in the absence of MAX, 

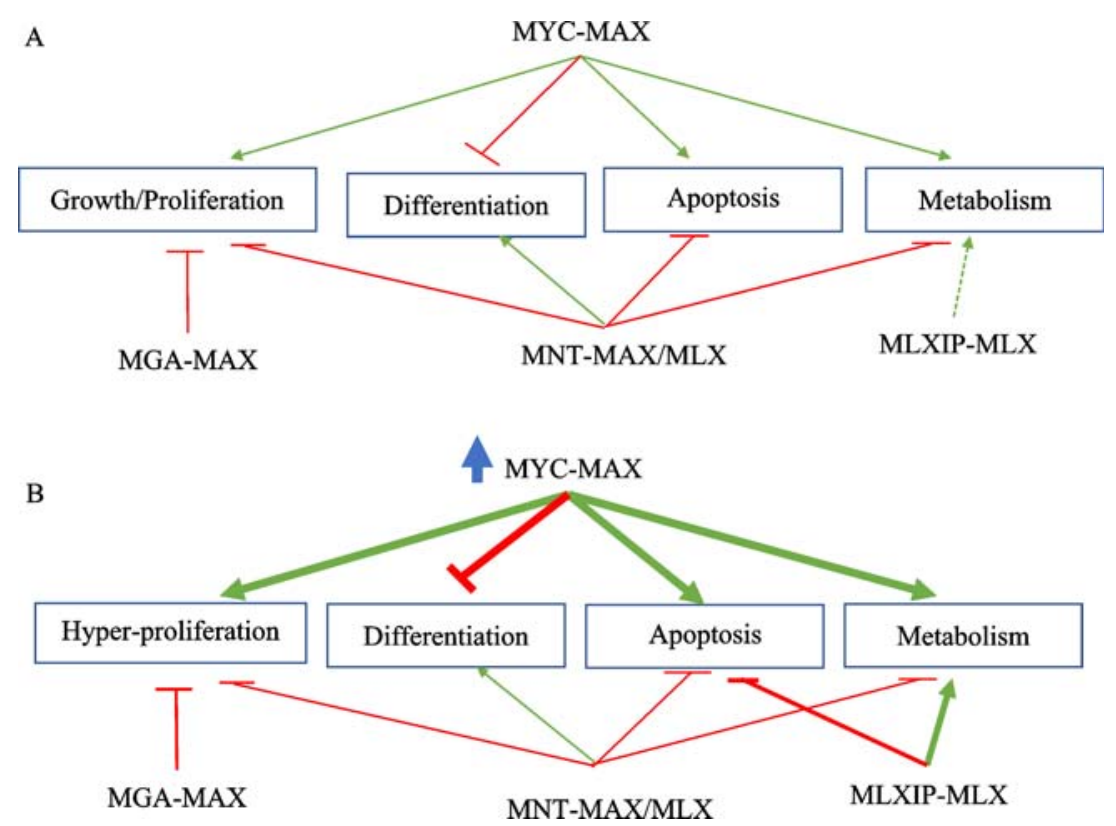

Fig. 5 A hypothetical representation of two states of the MYC network and their impact on gene expression programs that influence growth, proliferation, differentiation, apoptosis and metabolism. (A) A balanced network in which gene expression is controlled through normal endogenous regulation of the MYC network. Transcriptional effects of MYC-MAX are balanced by MNT (heterodimerized with either MAX or MLX), MGAMAX, and, under conditions of stress, by MLXIP-MLX or MLXIPL-MLX. (B) An unbalanced network due to deregulation of MYC expression. In this state MYC-MAX suppresses differentiation, reprograms metabolism, and triggers the apoptotic pathway. The suppressive effects of MGA-MAX and MNT-MAX/MLX on proliferation are overwhelmed by MYC-MAX which contributes to suppression of MYC-induced apoptosis. Increased nuclear accumulation of MLXIP-MLX (in response to deregulated MYC and/or metabolic stress) adjusts metabolic reprogramming by MYC-MAX and further reduces apoptosis. The effects on gene expression are presumed to occur through genomic binding and co-occupancy by network members. Green arrows, transcriptional activation; red arrows, transcriptional repression. Arrow width proportional to estimated transcriptional effect. Diagram adapted from [5].

as suggested by MAX deletion experiments in Drosophila [105].

\section{Functional interactions between MYC-MAX and MLXIP-MLX}

Given that deregulated MYC has been shown to stimulate aerobic glycolysis and to reprogram multiple aspects of metabolism [106] it is not entirely unexpected that important functional interactions exist between MYCMAX and the MLXIP-MLX modules [11,21]. One aspect of this interaction was revealed in a recent study showing that, in a number of MYC-driven cancer cell lines (i.e., cells in which MYC is clearly deregulated and which depend on continued MYC expression for growth), the loss or suppression of MLXIP or MLX results in growth arrest and apoptosis, even though high MYC levels are maintained [107]. In a neuroblastoma cell line, MYCMAX and MLXIP-MLX were found to cooperatively regulate transcription of a subset of genes involved in metabolism. These include genes encoding fatty acid synthase (FASN) and sterol CoA-desaturase (SCD), both rate limiting for fatty acid biosynthesis. Metabolomic and carbon tracing experiments demonstrated a significantly decreased contribution to the production of palmitate, an initial step in the fatty acid biosynthesis pathway. The resulting metabolic stress and cell death can be rescued by either restoring MLXIP expression, or by addition of the C18.1 monounsaturated fatty acid, oleate, supporting a critical role for lipid production in the survival of these tumor cells [107]. Importantly, cells in which MYC expression is under normal regulation are largely unaffected by MLXIP-MLX loss of function. This suggests that at least one aspect of MLXIP-MLX cooperativity with MYC-MAX is to modulate the expression of metabolic genes, such as FASN and SCD, in order to meet the increased metabolic demands imposed by MYC-MAX driven cell transformation. In this scenario, deregulated MYC, unlinked from its normal physiologic regulators, drives anabolic metabolism and proliferation regardless of the availability of extracellular factors that are normally limiting for cell growth. This imbalance is expected to result in stress, eventually leading to growth arrest and apoptosis. However the stress response is at least partially attenuated by MLXIP-MLX which remains responsive to nutrient availability and can be thought of as a transcriptional gatekeeper by adjusting gene expression in order to match metabolic demand [108] (Fig. 5). 


\section{Involvement of MLXIP-MLX in the response to cellular stress}

If MLXIP-MLX functions to suppress stress in MYCdriven cancers we might anticipate its involvement in other forms of stress response. In this regard it has been reported that MLX in C. elegans stimulates expression of autophagy genes subsequent to golgi disruption [109] and acts to inhibit TOR to promote longevity [110]. This is consistent with a report that MLX is responsive to, and suppresses, golgi stress in mammalian cell culture [110]. In addition, MLX null mice fail to regenerate muscle, compared to the rapid recovery of wildtype mice, following damage due to cardiotoxin treatment [111]. Furthermore, normal physiologic processes entailing high metabolic demand, such as T cell activation and spermatogenesis, are impaired in the absence of MLX (P.A.C. and B.W.F. manuscript in preparation). While MYC is known to be critical in both spermatogenesis [112] and $\mathrm{T}$ cell activation [30], it is unclear whether MLXIP-MLX are acting cooperatively with MYC-MAX in the manner described above for MYC-driven neuroblastoma and other tumor types [107]. Moreover in a triple negative breast cancer (TNBC) cell line, and in BRAF mutant melanomas, MYC and MLXIP appear to have opposing activities, at least with regards to inducing expression of the TXNIP target gene which encodes a negative regulator of glucose transport $[113,114]$. For example, in the highly glycolytic TNBC line, knockdown of MYC leads to MLXIPmediated activation of TXNIP and decreased glucose uptake, indicating that MYC and MLXIP are acting antagonistically [113]. These diverse examples imply that the precise mechanisms underlying functional interactions between MYC-MAX and MLXIP-MLX are likely to depend on the specific biological context in which they occur and the unique bioenergetic or metabolic wiring present in those systems. Nonetheless, the available data support the overarching concept that these network interactions serve to modulate metabolism at the transcriptional level in order to balance nutrient supply and demand and influence cell fate [115].

\section{Genomic binding by MYC network heterodimers}

The integrated functions of the network are dependent on the binding of heterodimeric complexes of network members to DNA (Fig. 1). Indeed, it is reasonable to surmise that the cooperative or antagonistic interactions among module heterodimers arises from direct interactions between these proteins at target gene loci. Genomic occupancies of many of these proteins have been mapped by the Encode project (www.encodeproject.org). However, as mentioned above, MYC-MAX binds to thousands of genes whose identity is dependent both on the nature of the cellular transcriptome and the abundance of MYC protein [40-42]. It is plausible to assume that binding by other network members will also be dependent on cellular context. Therefore, genomic occupancy studies of the MYC network will need to be carried out in biological settings in which network function is active and relevant and can be perturbed to reveal its critical functions.

A recent study employing in vitro selection for co-bound factors found that cooperative transcription factor binding to DNA is surprisingly common, estimating that $\sim 25000$ distinct pairs of transcription factors may be associated with mammalian genomic DNA [116](for review see [117]). Cooperative binding is thought to contribute to the presence of dense clusters of transcription factors as observed primarily in nucleosome-free regions [118]. At the simplest level the dimerization of MAX with MYC or MXD proteins represents cooperative binding since these proteins do not recognize DNA as monomers nor form stable homodimers. However, an important question is whether heterodimers from the different arms of the MYC network interact cooperatively with DNA. Interestingly, structural studies indicate that MYC-MAX heterodimers could themselves dimerize to form heterotetramers in solution [1] and MLXIPL-MLX is thought to function as a dimer of dimers on the tandem ChoRE E-boxes in a cooperative manner [119]. Detailed analysis remains to be carried out on cooperative binding by different network heterodimers, but initial work supports the idea that MYCN-MAX and MLXIP-MLX can co-occupy the TXNIP promoter region and act to cooperatively augment TXNIP expression in MYC-driven neuroblastoma [107]. Cooperative binding is likely to account for the cooperative effects of MYC-MAX and MLXIP-MLX on expression of other metabolic genes and may account for antagonistic activity of MYC and MXD proteins (Fig. 5).

A detailed description of the network will involve mapping the genomic binding sites of all members of the three network modules as well as the effects of genetic and chemical perturbation of the network on genomic binding and expression of bound genes. In addition it is worth noting that the MYC network itself belongs to the larger super-family of bHLH transcription factors that recognize E-box DNA [120]. These include proteins such as CLOCK-BMAL and HIF among many others, whose functions impinge on MYC network activity [121,122]. Given the importance of the MYC network, we anticipate that the elucidation of its genomic binding, functional interactions, and its integration with other cellular transcriptional networks, will lead to deeper insights into normal cellular functions and provide new pathways and targets for cancer therapy.

\section{Acknowledgements}

The authors thank Daniel Diolaiti, Don Ayer, and Peter Hurlin as 
well as other past and present members of the Eisenman laboratory for many discussions concerning MYC and its network. Research conducted by the authors mentioned in this review was supported by grants from NIH/NCI (Nos. RO1CA20525 and RO1CA57138) and a Hartwell Innovation Fund Pilot grant (to R.N.E.).

\section{Compliance with ethics guidelines}

Patrick A. Carroll, Brian W. Freie, Haritha Mathsyaraja, and Robert N. Eisenman declare that they have no conflicts of interest. This manuscript is a review article and does not involve a research protocol requiring approval by the relevant institutional review board or ethics committee. Research described from the authors' laboratory is in full compliance with institutional and national guidelines for the care and use of laboratory animals.

Open Access This article is distributed under the terms of the Creative Commons Attribution 4.0 International License (http:// creativecommons.org/licenses/by/4.0/), which permits unrestricted use, distribution, and reproduction in any medium, provided the appropriate credit is given to the original author(s) and the source, and a link is provided to the Creative Commons license, which indicates if changes are made.

\section{References}

1. Nair SK, Burley SK. X-ray structures of Myc-Max and Mad-Max recognizing DNA. Molecular bases of regulation by protooncogenic transcription factors. Cell 2003; 112(2): 193-205

2. Conacci-Sorrell M, Ngouenet C, Eisenman RN. Myc-Nick: a cytoplasmic cleavage product of Myc that promotes $\alpha$-tubulin acetylation and cell differentiation. Cell 2010;142(3):480-493

3. Davidson EH, Rast JP, Oliveri P, Ransick A, Calestani C, Yuh CH, Minokawa T, Amore G, Hinman V, Arenas-Mena C, Otim O, Brown CT, Livi CB, Lee PY, Revilla R, Rust AG, Pan Z, Schilstra MJ, Clarke PJ, Arnone MI, Rowen L, Cameron RA, McClay DR, Hood L, Bolouri H. A genomic regulatory network for development. Science 2002; 295(5560): 1669-1678

4. Newman MEJ. Modularity and community structure in networks. Proc Natl Acad Sci USA 2006; 103(23): 8577-8582

5. Diolaiti D, McFerrin L, Carroll PA, Eisenman RN. Functional interactions among members of the MAX and MLX transcriptional network during oncogenesis. Biochim Biophys Acta 2015; 1849 (5): 484-500

6. Patel VR, Eckel-Mahan K, Sassone-Corsi P, Baldi P. CircadiOmics: integrating circadian genomics, transcriptomics, proteomics and metabolomics. Nat Methods 2012; 9(8): 772-773

7. Kim J, Chu J, Shen X, Wang J, Orkin SH. An extended transcriptional network for pluripotency of embryonic stem cells. Cell 2008; 132(6): 1049-1061

8. Chronis C, Fiziev P, Papp B, Butz S, Bonora G, Sabri S, Ernst J, Plath K. Cooperative binding of transcription factors orchestrates reprogramming. Cell 2017; 168(3): 442-459.e20

9. Kueh HY, Rothenberg EV. Regulatory gene network circuits underlying $\mathrm{T}$ cell development from multipotent progenitors.
Wiley Interdiscip Rev Syst Biol Med 2012; 4(1): 79-102

10. Conacci-Sorrell M, McFerrin L, Eisenman RN. An overview of MYC and its interactome. Cold Spring Harb Perspect Med 2014;4 (1):a014357

11. O'Shea JM, Ayer DE. Coordination of nutrient availability and utilization by MAX- and MLX-centered transcription networks. Cold Spring Harb Perspect Med 2013; 3(9): a014258

12. Peterson CW, Ayer DE. An extended Myc network contributes to glucose homeostasis in cancer and diabetes. Front Biosci (Landmark Ed) 2011;16:2206-2223

13. Sloan EJ, Ayer DE. Myc, mondo, and metabolism. Genes Cancer 2010; 1(6): 587-596

14. Blackwood EM, Eisenman RN. Max: a helix-loop-helix zipper protein that forms a sequence-specific DNA binding complex with Myc. Science 1991; 251(4998):1211-1217

15. Billin AN, Eilers AL, Queva C, Ayer DE. Mlx, a novel Max-like BHLHZip protein that interacts with the Max network of transcription factors. J Biol Chem 1999; 274(51): 36344-36350

16. Berberich SJ, Cole MD. Casein kinase II inhibits the DNA-binding activity of Max homodimers but not Myc/Max heterodimers. Genes Dev 1992; 6(2): 166-176

17. Meroni G, Cairo S, Merla G, Messali S, Brent R, Ballabio A, Reymond A. Mlx, a new Max-like bHLHZip family member: the center stage of a novel transcription factors regulatory pathway? Oncogene 2000; 19(29): 3266-3277

18. Hurlin PJ, Quéva C, Eisenman RN. Mnt, a novel Max-interacting protein is coexpressed with Myc in proliferating cells and mediates repression at Myc binding sites. Genes Dev 1997; 11(1): 44-58

19. Ayer DE, Eisenman RN. A switch from Myc:Max to Mad:Max heterocomplexes accompanies monocyte/macrophage differentiation. Genes Dev 1993; 7(11): 2110-2119

20. Hann SR, Eisenman RN. Proteins encoded by the human c-myc oncogene: differential expression in neoplastic cells. Mol Cell Biol 1984; 4(11): 2486-2497

21. Billin AN, Ayer DE. The Mlx network: evidence for a parallel Max-like transcriptional network that regulates energy metabolism. Curr Top Microbiol Immunol 2006; 302: 255-278

22. Billin AN, Eilers AL, Coulter KL, Logan JS, Ayer DE. MondoA, a novel basic helix-loop-helix-leucine zipper transcriptional activator that constitutes a positive branch of a max-like network. Mol Cell Biol 2000; 20(23): 8845-8854

23. Roussel M, Saule S, Lagrou C, Rommens C, Beug H, Graf T, Stehelin D. Three new types of viral oncogene of cellular origin specific for haematopoietic cell transformation. Nature 1979; 281 (5731): 452-455

24. Sheiness D, Bishop JM. DNA and RNA from uninfected vertebrate cells contain nucleotide sequences related to the putative transforming gene of avian myelocytomatosis virus. J Virol 1979; 31(2): 514-521

25. Schaub FX, Dhankani V, Berger AC, Trivedi M, Richardson AB, Shaw R, Zhao W, Zhang X, Ventura A, Liu Y, Ayer DE, Hurlin PJ, Cherniack AD, Eisenman RN, Bernard B, Grandori C; Cancer Genome Atlas Network. Pan-cancer alterations in MYC oncogene and its proximal network across the cancer genome atlas. Cell Syst 2018; 6: 282-300

26. Meyer N, Penn LZ. Reflecting on 25 years with MYC. Nat Rev Cancer 2008; 8(12):976-990 
27. Eilers M, Eisenman RN. Myc's broad reach. Genes Dev 2008; 22 (20): 2755-2766

28. Armelin HA, Armelin MCS, Kelly K, Stewart T, Leder P, Cochran $\mathrm{BH}$, Stiles CD. Functional role for c-myc in mitogenic response to platelet-derived growth factor. Nature 1984; 310(5979): 655660

29. Kelly K, Cochran BH, Stiles CD, Leder P. Cell-specific regulation of the c-myc gene by lymphocyte mitogens and platelet-derived growth factor. Cell 1983; 35(3 Pt 2): 603-610

30. Wang R, Dillon CP, Shi LZ, Milasta S, Carter R, Finkelstein D, McCormick LL, Fitzgerald P, Chi H, Munger J, Green DR. The transcription factor Myc controls metabolic reprogramming upon $\mathrm{T}$ lymphocyte activation. Immunity 2011;35(6):871-882

31. Gabay M, Li Y, Felsher DW. MYC activation is a hallmark of cancer initiation and maintenance. Cold Spring Harb Perspect Med 2014; 4(6): a014241

32. Okuyama H, Endo H, Akashika T, Kato K, Inoue M. Downregulation of c-MYC protein levels contributes to cancer cell survival under dual deficiency of oxygen and glucose. Cancer Res 2010; 70(24): 10213-10223

33. Shachaf CM, Gentles AJ, Elchuri S, Sahoo D, Soen Y, Sharpe O, Perez OD, Chang M, Mitchel D, Robinson WH, Dill D, Nolan GP, Plevritis SK, Felsher DW. Genomic and proteomic analysis reveals a threshold level of MYC required for tumor maintenance. Cancer Res 2008; 68(13): 5132-5142

34. Karlsson A, Giuriato S, Tang F, Fung-Weier J, Levan G, Felsher DW. Genomically complex lymphomas undergo sustained tumor regression upon MYC inactivation unless they acquire novel chromosomal translocations. Blood 2003; 101(7): 2797-2803

35. Thomas LR, Wang Q, Grieb BC, Phan J, Foshage AM, Sun Q, Olejniczak ET, Clark T, Dey S, Lorey S, Alicie B, Howard GC, Cawthon B, Ess KC, Eischen CM, Zhao Z, Fesik SW, Tansey WP. Interaction with WDR5 promotes target gene recognition and tumorigenesis by MYC. Mol Cell 2015; 58(3): 440-452

36. Guccione E, Martinato F, Finocchiaro G, Luzi L, Tizzoni L, Dall' Olio V, Zardo G, Nervi C, Bernard L, Amati B. Myc-binding-site recognition in the human genome is determined by chromatin context. Nat Cell Biol 2006; 8(7): 764-770

37. Wiese KE, Walz S, von Eyss B, Wolf E, Athineos D, Sansom O, Eilers M. The role of MIZ-1 in MYC-dependent tumorigenesis. Cold Spring Harb Perspect Med 2013; 3(12): a014290

38. Vo BT, Wolf E, Kawauchi D, Gebhardt A, Rehg JE, Finkelstein D, Walz S, Murphy BL, Youn YH, Han YG, Eilers M, Roussel MF. The interaction of Myc with Mizl defines medulloblastoma subgroup identity. Cancer Cell 2016; 29(1): 5-16

39. Hann SR. MYC cofactors: molecular switches controlling diverse biological outcomes. Cold Spring Harb Perspect Med 2014; 4(9): a014399

40. Lin CY, Lovén J, Rahl PB, Paranal RM, Burge CB, Bradner JE, Lee TI, Young RA. Transcriptional amplification in tumor cells with elevated c-Myc. Cell 2012; 151(1): 56-67

41. Rahl PB, Lin CY, Seila AC, Flynn RA, McCuine S, Burge CB, Sharp PA, Young RA. c-Myc regulates transcriptional pause release. Cell 2010; 141(3):432-445

42. Nie Z, Hu G, Wei G, Cui K, Yamane A, Resch W, Wang R, Green DR, Tessarollo L, Casellas R, Zhao K, Levens D. c-Myc is a universal amplifier of expressed genes in lymphocytes and embryonic stem cells. Cell 2012; 151(1): 68-79

43. Lorenzin F, Benary U, Baluapuri A, Walz S, Jung LA, von Eyss B, Kisker C, Wolf J, Eilers M, Wolf E. Different promoter affinities account for specificity in MYC-dependent gene regulation. eLife 2016; 5: e15161

44. Whyte WA, Orlando DA, Hnisz D, Abraham BJ, Lin CY, Kagey $\mathrm{MH}$, Rahl PB, Lee TI, Young RA. Master transcription factors and mediator establish super-enhancers at key cell identity genes. Cell 2013; 153(2): 307-319

45. Wolf E, Lin CY, Eilers M, Levens DL. Taming of the beast: shaping Myc-dependent amplification. Trends Cell Biol 2015; 25 (4): 241-248

46. Kress TR, Sabò A, Amati B. MYC: connecting selective transcriptional control to global RNA production. Nat Rev Cancer 2015; 15(10): 593-607

47. Zeid R, Lawlor MA, Poon E, Reyes JM, Fulciniti M, Lopez MA, Scott TG, Nabet B, Erb MA, Winter GE, Jacobson Z, Polaski DR, Karlin KL, Hirsch RA, Munshi NP, Westbrook TF, Chesler L, Lin CY, Bradner JE. Enhancer invasion shapes MYCN-dependent transcriptional amplification in neuroblastoma. Nat Genet 2018; 50 (4): 515-523

48. Meroni G, Reymond A, Alcalay M, Borsani G, Tanigami A, Tonlorenzi R, Lo Nigro C, Messali S, Zollo M, Ledbetter DH, Brent R, Ballabio A, Carrozzo R. Rox, a novel bHLHZip protein expressed in quiescent cells that heterodimerizes with Max, binds a non-canonical $\mathrm{E}$ box and acts as a transcriptional repressor. EMBO J 1997; 16(10): 2892-2906

49. Hurlin PJ, Quéva C, Koskinen PJ, Steingrímsson E, Ayer DE, Copeland NG, Jenkins NA, Eisenman RN. Mad3 and Mad4: novel Max-interacting transcriptional repressors that suppress c-myc dependent transformation and are expressed during neural and epidermal differentiation. EMBO J 1995; 14(22): 5646-5659

50. Zervos AS, Gyuris J, Brent R. Mxi1, a protein that specifically interacts with Max to bind Myc-Max recognition sites. Cell 1993; 72(2): 223-232

51. Ayer DE, Kretzner L, Eisenman RN. Mad: a heterodimeric partner for Max that antagonizes Myc transcriptional activity. Cell 1993; 72(2): 211-222

52. Hurlin PJ, Steingrìmsson E, Copeland NG, Jenkins NA, Eisenman RN. Mga, a dual-specificity transcription factor that interacts with Max and contains a T-domain DNA-binding motif. EMBO J 1999; 18(24): 7019-7028

53. Papaioannou VE, Silver LM. The T-box gene family. BioEssays 1998; 20(1): 9-19

54. Kispert A, Koschorz B, Herrmann BG. The T protein encoded by Brachyury is a tissue-specific transcription factor. EMBO J 1995; 14(19): 4763-4772

55. Kispert A, Herrmann BG. The Brachyury gene encodes a novel DNA binding protein. EMBO J 1993; 12(8): 3211-3220

56. Ferré-D'Amaré AR, Prendergast GC, Ziff EB, Burley SK. Recognition by Max of its cognate DNA through a dimeric b/ HLH/Z domain. Nature 1993; 363(6424): 38-45

57. Brubaker K, Cowley SM, Huang K, Loo L, Yochum GS, Ayer DE, Eisenman RN, Radhakrishnan I. Solution structure of the interacting domains of the Mad-Sin3 complex: implications for recruitment of a chromatin-modifying complex. Cell 2000; 103(4): 655-665 
58. Ayer DE, Lawrence QA, Eisenman RN. Mad-Max transcriptional repression is mediated by ternary complex formation with mammalian homologs of yeast repressor Sin3. Cell 1995; 80(5): $767-776$

59. Zhang Y, Iratni R, Erdjument-Bromage H, Tempst P, Reinberg D. Histone deacetylases and SAP18, a novel polypeptide, are components of a human Sin3 complex. Cell 1997; 89(3): 357-364

60. Laherty CD, Yang WM, Sun JM, Davie JR, Seto E, Eisenman RN. Histone deacetylases associated with the $\mathrm{mSin} 3$ corepressor mediate mad transcriptional repression. Cell 1997; 89(3): 349-356

61. Hassig CA, Fleischer TC, Billin AN, Schreiber SL, Ayer DE. Histone deacetylase activity is required for full transcriptional repression by mSin3A. Cell 1997; 89(3): 341-347

62. Gao Z, Zhang J, Bonasio R, Strino F, Sawai A, Parisi F, Kluger Y, Reinberg D. PCGF homologs, CBX proteins, and RYBP define functionally distinct PRC1 family complexes. Mol Cell 2012; 45 (3): $344-356$

63. Ogawa H, Ishiguro K, Gaubatz S, Livingston DM, Nakatani Y. A complex with chromatin modifiers that occupies E2F- and Mycresponsive genes in G0 cells. Science 2002; 296(5570): 1132-1136

64. Endoh M, Endo TA, Shinga J, Hayashi K, Farcas A, Ma KW, Ito S, Sharif J, Endoh T, Onaga N, Nakayama M, Ishikura T, Masui O, Kessler BM, Suda T, Ohara O, Okuda A, Klose R, Koseki H. PCGF6-PRC1 suppresses premature differentiation of mouse embryonic stem cells by regulating germ cell-related genes. eLife 2017; 6:e21064

65. Suzuki A, Hirasaki M, Hishida T, Wu J, Okamura D, Ueda A, Nishimoto M, Nakachi Y, Mizuno Y, Okazaki Y, Matsui Y, Izpisua Belmonte JC, Okuda A. Loss of MAX results in meiotic entry in mouse embryonic and germline stem cells. Nat Commun 2016; 7: 11056

66. McFerrin LG, Atchley WR. Evolution of the Max and Mlx networks in animals. Genome Biol Evol 2011; 3:915-937

67. Washkowitz AJ, Schall C, Zhang K, Wurst W, Floss T, Mager J, Papaioannou VE. Mga is essential for the survival of pluripotent cells during peri-implantation development. Development 2015; 142(1): 31-40

68. Sun Y, Tseng WC, Fan X, Ball R, Dougan ST. Extraembryonic signals under the control of MGA, Max, and Smad4 are required for dorsoventral patterning. Dev Cell 2014; 28(3): 322-334

69. Hu G, Kim J, Xu Q, Leng Y, Orkin SH, Elledge SJ. A genomewide RNAi screen identifies a new transcriptional module required for self-renewal. Genes Dev 2009; 23(7): 837-848

70. Sun QY, Ding LW, Tan KT, Chien W, Mayakonda A, Lin DC, Loh XY, Xiao JF, Meggendorfer M, Alpermann T, Garg M, Lim SL, Madan V, Hattori N, Nagata Y, Miyano S, Yeoh AE, Hou HA, Jiang YY, Takao S, Liu LZ, Tan SZ, Lill M, Hayashi M, Kinoshita A, Kantarjian HM, Kornblau SM, Ogawa S, Haferlach T, Yang H, Koeffler HP. Ordering of mutations in acute myeloid leukemia with partial tandem duplication of MLL (MLL-PTD). Leukemia 2017; 31(1): 1-10

71. Romero OA, Torres-Diz M, Pros E, Savola S, Gomez A, Moran S, Saez C, Iwakawa R, Villanueva A, Montuenga LM, Kohno T, Yokota J, Sanchez-Cespedes M. MAX inactivation in small cell lung cancer disrupts MYC-SWI/SNF programs and is synthetic lethal with BRG1. Cancer Discov 2014; 4(3): 292-303

72. De Paoli L, Cerri M, Monti S, Rasi S, Spina V, Bruscaggin A,
Greco M, Ciardullo C, Famà R, Cresta S, Maffei R, Ladetto M, Martini M, Laurenti L, Forconi F, Marasca R, Larocca LM, Bertoni F, Gaidano G, Rossi D. MGA, a suppressor of MYC, is recurrently inactivated in high risk chronic lymphocytic leukemia. Leuk Lymphoma 2013; 54(5): 1087-1090

73. Chigrinova E, Rinaldi A, Kwee I, Rossi D, Rancoita PM, Strefford JC, Oscier D, Stamatopoulos K, Papadaki T, Berger F, Young KH, Murray F, Rosenquist R, Greiner TC, Chan WC, Orlandi EM, Lucioni M, Marasca R, Inghirami $G$, Ladetto $M$, Forconi $F$, Cogliatti S, Votavova H, Swerdlow SH, Stilgenbauer S, Piris MA, Matolcsy A, Spagnolo D, Nikitin E, Zamò A, Gattei V, Bhagat G, Ott G, Zucca E, Gaidano G, Bertoni F. Two main genetic pathways lead to the transformation of chronic lymphocytic leukemia to Richter syndrome. Blood 2013; 122(15): 2673-2682

74. Edelmann J, Holzmann K, Miller F, Winkler D, Bühler A, Zenz T, Bullinger L, Kühn MW, Gerhardinger A, Bloehdorn J, Radtke I, Su X, Ma J, Pounds S, Hallek M, Lichter P, Korbel J, Busch R, Mertens D, Downing JR, Stilgenbauer S, Döhner H. Highresolution genomic profiling of chronic lymphocytic leukemia reveals new recurrent genomic alterations. Blood 2012; 120(24): 4783-4794

75. McFerrin LG, Atchley WR. A novel N-terminal domain may dictate the glucose response of Mondo proteins. PLoS One 2012; 7 (4): e34803

76. Arden C, Tudhope SJ, Petrie JL, Al-Oanzi ZH, Cullen KS, Lange AJ, Towle HC, Agius L. Fructose 2,6-bisphosphate is essential for glucose-regulated gene transcription of glucose-6-phosphatase and other ChREBP target genes in hepatocytes. Biochem J 2012; 443 (1): 111-123

77. Petrie JL, Al-Oanzi ZH, Arden C, Tudhope SJ, Mann J, Kieswich J, Yaqoob MM, Towle HC, Agius L. Glucose induces protein targeting to glycogen in hepatocytes by fructose 2,6-bisphosphatemediated recruitment of MondoA to the promoter. Mol Cell Biol 2013; 33(4): 725-738

78. Sans CL, Satterwhite DJ, Stoltzman CA, Breen KT, Ayer DE. MondoA-Mlx heterodimers are candidate sensors of cellular energy status: mitochondrial localization and direct regulation of glycolysis. Mol Cell Biol 2006; 26(13): 4863-4871

79. Peterson CW, Stoltzman CA, Sighinolfi MP, Han KS, Ayer DE. Glucose controls nuclear accumulation, promoter binding, and transcriptional activity of the MondoA-Mlx heterodimer. Mol Cell Biol 2010; 30(12):2887-2895

80. Stoltzman CA, Peterson CW, Breen KT, Muoio DM, Billin AN, Ayer DE. Glucose sensing by MondoA:Mlx complexes: a role for hexokinases and direct regulation of thioredoxin-interacting protein expression. Proc Natl Acad Sci U S A 2008; 105 (19):6912-6917

81. Mattila J, Havula E, Suominen E, Teesalu M, Surakka I, Hynynen R, Kilpinen H, Väänänen J, Hovatta I, Käkelä R, Ripatti S, Sandmann T, Hietakangas V. Mondo-Mlx mediates organismal sugar sensing through the Gli-similar transcription factor sugarbabe. Cell Reports 2015; 13(2): 350-364

82. Havula E, Teesalu M, Hyötyläinen T, Seppälä H, Hasygar K, Auvinen P, Orešič M, Sandmann T, Hietakangas V. Mondo/ ChREBP-Mlx-regulated transcriptional network is essential for dietary sugar tolerance in Drosophila. PLoS Genet 2013; 9(4): e1003438 
83. Iizuka $\mathrm{K}$. The transcription factor carbohydrate-response elementbinding protein (ChREBP): a possible link between metabolic disease and cancer. Biochim Biophys Acta 2017; 1863(2): 474485

84. Dang CV, Eisenman RN. Myc and the Pathway to Cancer. Cold Spring Harbor, N.Y.: Cold Spring Harbor Press, 2014

85. Comino-Mendez I, Gracia-Aznarez FJ, Schiavi F, Landa I, Leandro-Garcia LJ, Leton R, Honrado E, Ramos-Medina R, Caronia D, Pita G, Gomez-Grana A, de Cubas AA, Inglada-Perez L, Maliszewska A, Taschin E, Bobisse S, Pica G, Loli P, Hernandez-Lavado R, Diaz JA, Gomez-Morales M, GonzalezNeira A, Roncador G, Rodriguez-Antona C, Benitez J, Mannelli M, Opocher G, Robledo M, Cascon A. Exome sequencing identifies MAX mutations as a cause of hereditary pheochromocytoma. Nat Genet 2011;43(7):663-667

86. Toyo-oka K, Bowen TJ, Hirotsune S, Li Z, Jain S, Ota S, EscoubetLozach L, Garcia-Bassets I, Lozach J, Rosenfeld MG, Glass CK, Eisenman R, Ren B, Hurlin P, Wynshaw-Boris A. Mnt-deficient mammary glands exhibit impaired involution and tumors with characteristics of myc overexpression. Cancer Res 2006; 66(11): $5565-5573$

87. Dezfouli S, Bakke A, Huang J, Wynshaw-Boris A, Hurlin PJ. Inflammatory disease and lymphomagenesis caused by deletion of the Myc antagonist Mnt in T cells. Mol Cell Biol 2006; 26(6): 2080-2092

88. Lahoz EG, Xu L, Schreiber-Agus N, DePinho RA. Suppression of Myc, but not E1a, transformation activity by Max-associated proteins, Mad and Mxi1. Proc Natl Acad Sci USA 1994; 91(12): 5503-5507

89. Iritani BM, Delrow J, Grandori C, Gomez I, Klacking M, Carlos LS, Eisenman RN. Modulation of T-lymphocyte development, growth and cell size by the Myc antagonist and transcriptional repressor Mad1. Embo J 2002; 21(18):4820-4830

90. Roussel MF, Ashmun RA, Sherr CJ, Eisenman RN, Ayer DE. Inhibition of cell proliferation by the Mad1 transcriptional repressor. Mol Cell Biol 1996; 16(6): 2796-2801

91. Marcotte R, Qian JF, Chen J, Wang E. hMad4, c-Myc endogenous inhibitor, induces a replicative senescence-like state when overexpressed in human fibroblasts. J Cell Biochem 2003; 89(3): 576588

92. Walker W, Zhou ZQ, Ota S, Wynshaw-Boris A, Hurlin PJ. MntMax to Myc-Max complex switching regulates cell cycle entry. J Cell Biol 2005; 169(3): 405-413

93. Link JM, Ota S, Zhou ZQ, Daniel CJ, Sears RC, Hurlin PJ. A critical role for Mnt in Myc-driven T-cell proliferation and oncogenesis. Proc Natl Acad Sci USA 2012; 109(48): 1968519690

94. Yang G, Hurlin PJ. MNT and emerging concepts of MNT-MYC antagonism. Genes (Basel) 2017; 8(2): E83

95. Yun JS, Rust JM, Ishimaru T, Diaz E. A novel role of the Mad family member Mad3 in cerebellar granule neuron precursor proliferation. Mol Cell Biol 2007; 27(23):8178-8189

96. Quéva C, McArthur GA, Iritani BM, Eisenman RN. Targeted deletion of the S-phase-specific Myc antagonist Mad3 sensitizes neuronal and lymphoid cells to radiation-induced apoptosis. Mol Cell Biol 2001; 21(3): 703-712

97. Hooker CW, Hurlin PJ. Of Myc and Mnt. J Cell Sci 2006; 119(Pt
2): $208-216$

98. Bouchard C, Dittrich O, Kiermaier A, Dohmann K, Menkel A, Eilers M, Lüscher B. Regulation of cyclin D2 gene expression by the Myc/Max/Mad network: Myc-dependent TRRAP recruitment and histone acetylation at the cyclin D2 promoter. Genes Dev 2001; 15(16): 2042-2047

99. Pierce SB, Yost C, Anderson SA, Flynn EM, Delrow J, Eisenman RN. Drosophila growth and development in the absence of dMyc and dMnt. Dev Biol 2008; 315(2): 303-316

100. Beall EL, Bell M, Georlette D, Botchan MR. Dm-myb mutant lethality in Drosophila is dependent upon mip130: positive and negative regulation of DNA replication. Genes Dev 2004; 18(14): $1667-1680$

101. Frolov MV, Huen DS, Stevaux O, Dimova D, Balczarek-Strang K, Elsdon M, Dyson NJ. Functional antagonism between E2F family members. Genes Dev 2001; 15(16): 2146-2160

102. Welcker M, Orian A, Jin J, Grim JE, Harper JW, Eisenman RN, Clurman BE. The Fbw7 tumor suppressor regulates glycogen synthase kinase 3 phosphorylation-dependent c-Myc protein degradation. Proc Natl Acad Sci USA 2004; 101(24): 9085-9090

103. Farrell A, Sears RC. MYC Degradation. Cold Spring Harb Prespect Med 2014; 4:a014365

104. Zhu J, Blenis J, Yuan J. Activation of PI3K/Akt and MAPK pathways regulates Myc-mediated transcription by phosphorylating and promoting the degradation of Mad1. Proc Natl Acad Sci USA 2008; 105(18): 6584-6589

105. Steiger D, Furrer M, Schwinkendorf D, Gallant P. Maxindependent functions of Myc in Drosophila melanogaster. Nat Genet 2008; 40(9):1084-1091

106. Dejure FR, Eilers M. MYC and tumor metabolism: chicken and egg. EMBO J 2017; 36(23): 3409-3420

107. Carroll PA, Diolaiti D, McFerrin L, Gu H, Djukovic D, Du J, Cheng PF, Anderson S, Ulrich M, Hurley JB, Raftery D, Ayer DE, Eisenman RN. Deregulated Myc requires MondoA/Mlx for metabolic reprogramming and tumorigenesis. Cancer Cell 2015; 27(2): 271-285

108. Chan LN, Chen Z, Braas D, Lee JW, Xiao G, Geng H, Cosgun KN, Hurtz C, Shojaee S, Cazzaniga V, Schjerven H, Ernst T, Hochhaus A, Kornblau SM, Konopleva M, Pufall MA, Cazzaniga G, Liu GJ, Milne TA, Koeffler HP, Ross TS, Sánchez-García I, Borkhardt A, Yamamoto KR, Dickins RA, Graeber TG, Müschen M. Metabolic gatekeeper function of B-lymphoid transcription factors. Nature 2017; 542(7642): 479-483

109. Nakamura S, Karalay Ö, Jäger PS, Horikawa M, Klein C, Nakamura K, Latza C, Templer SE, Dieterich C, Antebi A. Mondo complexes regulate TFEB via TOR inhibition to promote longevity in response to gonadal signals. Nat Commun 2016; 7 : 10944

110. Taniguchi M, Sasaki-Osugi K, Oku M, Sawaguchi S, Tanakura S, Kawai Y, Wakabayashi S, Yoshida H. MLX Is a transcriptional repressor of the mammalian Golgi stress response. Cell Struct Funct 2016; 41(2): 93-104

111. Hunt LC, Xu B, Finkelstein D, Fan Y, Carroll PA, Cheng PF, Eisenman RN, Demontis F. The glucose-sensing transcription factor MLX promotes myogenesis via myokine signaling. Genes Dev 2015; 29(23): 2475-2489

112. Kanatsu-Shinohara M, Tanaka T, Ogonuki N, Ogura A, Morimoto 
H, Cheng PF, Eisenman RN, Trumpp A, Shinohara T. Myc/Mycnmediated glycolysis enhances mouse spermatogonial stem cell self-renewal. Genes Dev 2016; 30(23): 2637-2648

113. Shen L, O'Shea JM, Kaadige MR, Cunha S, Wilde BR, Cohen AL, Welm AL, Ayer DE. Metabolic reprogramming in triple-negative breast cancer through Myc suppression of TXNIP. Proc Natl Acad Sci USA 2015; 112(17): 5425-5430

114. Parmenter TJ, Kleinschmidt M, Kinross KM, Bond ST, Li J, Kaadige MR, Rao A, Sheppard KE, Hugo W, Pupo GM, Pearson RB, McGee SL, Long GV, Scolyer RA, Rizos H, Lo RS, Cullinane C, Ayer DE, Ribas A, Johnstone RW, Hicks RJ, McArthur GA. Response of BRAF-mutant melanoma to BRAF inhibition is mediated by a network of transcriptional regulators of glycolysis. Cancer Discov 2014; 4(4): 423-433

115. Wilde BR, Ayer DE. Interactions between Myc and MondoA transcription factors in metabolism and tumourigenesis. $\mathrm{Br} \mathrm{J}$ Cancer 2015; 113(11): 1529-1533

116. Jolma A, Yin Y, Nitta KR, Dave K, Popov A, Taipale M, Enge M, Kivioja T, Morgunova E, Taipale J. DNA-dependent formation of transcription factor pairs alters their binding specificity. Nature 2015; 527(7578): 384-388

117. Morgunova E, Taipale J. Structural perspective of cooperative transcription factor binding. Curr Opin Struct Biol 2017; 47: 1-8

118. Yan J, Enge M, Whitington T, Dave K, Liu J, Sur I, Schmierer B, Jolma A, Kivioja T, Taipale M, Taipale J. Transcription factor binding in human cells occurs in dense clusters formed around cohesin anchor sites. Cell 2013; 154(4): 801-813

119. Ma L, Sham YY, Walters KJ, Towle HC. A critical role for the loop region of the basic helix-loop-helix/leucine zipper protein Mlx in DNA binding and glucose-regulated transcription. Nucleic Acids Res 2007; 35(1): 35-44

120. Skinner MK, Rawls A, Wilson-Rawls J, Roalson EH. Basic helixloop-helix transcription factor gene family phylogenetics and nomenclature. Differentiation 2010; 80(1): 1-8

121. Altman BJ, Hsieh AL, Sengupta A, Krishnanaiah SY, Stine ZE, Walton ZE, Gouw AM, Venkataraman A, Li B, Goraksha-Hicks P, Diskin SJ, Bellovin DI, Simon MC, Rathmell JC, Lazar MA, Maris JM, Felsher DW, Hogenesch JB, Weljie AM, Dang CV. MYC disrupts the circadian clock and metabolism in cancer cells. Cell Metab 2015; 22(6): 1009-1019

122. Qing G, Skuli N, Mayes PA, Pawel B, Martinez D, Maris JM, Simon MC. Combinatorial regulation of neuroblastoma tumor progression by N-Myc and hypoxia inducible factor HIF-1 $\alpha$. Cancer Res 2010; 70(24):10351-10361 